\title{
Assessing Problem-Framing Skills in Secondary School Students Using the Needs Identification Canvas
}

\section{Dr. Patrick James Herak, The Ohio State University}

Dr. Herak is a four time graduate of The Ohio State University: BSE (Science Education), MS (Env Sci), MS (Civil Eng), and PhD (STEM Education). As an undergrad he was a member of The Ohio State University Marching Band for 5-years and can still be found playing with the TBDBITL Alumni Band.

Dr. Herak was a secondary science teacher for 18-years, primarily for Westerville City Schools. However, he did take a leave of absence to teach at Aldenham School near London (UK). Dr. Herak has served as an adjunct professor at Central Ohio Technical College (Environmental Science) and adjunct professor position at Ashland University - Columbus Branch (Science Education), a position he still currently holds. Dr. Herak is currently completing a Master's Degree in Foreign Secondary and Multilingual Education and serves as a Senior Lecturer in the College of Engineering at The Ohio State University.

Dr. Herak has presented at education conferences at the state, national and international level including the Science Education Council of Ohio, National Science Teachers Association, International Consortium of Research in Science and Math Education, First Year Engineering Education conference and American Society for Engineering Education conference.

\section{Miss Meg E West, The Ohio State University}

Meg E. West is an engineering education graduate student at The Ohio State University. She is a graduate teaching and research associate for the Department of Engineering Education.

\section{Dr. J. Blake Hylton, Ohio Northern University}

Dr. Hylton is an Assistant Professor of Mechanical Engineering and Coordinator of the First-Year Engineering experience for the T.J. Smull College of Engineering at Ohio Northern University. He previously completed his graduate studies in Mechanical Engineering at Purdue University, where he conducted research in both the School of Mechanical Engineering and the School of Engineering Education. Prior to Purdue, he completed his undergraduate work at the University of Tulsa, also in Mechanical Engineering. He currently teaches first-year engineering courses as well as various courses in Mechanical Engineering, primarily in the mechanics area. His pedagogical research areas include standards-based assessment and curriculum design, including the incorporation of entrepreneurial thinking into the engineering curriculum and especially as pertains to First-Year Engineering.

\section{Dr. Todd France, Ohio Northern University}

Todd France is the director of Ohio Northern University's Engineering Education program, which strives to prepare engineering educators for the 7-12 grade levels. Dr. France is also heavily involved in developing and facilitating the first-year engineering program at ONU. He earned his PhD from the University of Colorado Boulder where his research focused on pre-engineering education and project-based learning.

\section{Mr. Bruce Wellman, Olathe Northwest High School}

Bruce Wellman is a National Board Certified Teacher (NBCT, Chemistry) who teaches Engineering Chemistry as part of Engineering Academy at Olathe Northwest High School in Olathe, KS and serves as a Co-Principal Investigator on an NSF funded (DR K-12) research project entitled "Building Informed Designers". Wellman is a member of ASEE's Board of Directors' Committee on P-12 Engineering Education. Wellman completed his B.S. degree in general science (focus in chemistry) at Penn State University and his M.S. in Education at the University of Rochester (NY). He has taught overseas as an English teacher in French-speaking Africa as well as a chemistry/AP Chemistry teacher in the United States in rural, urban, and suburban settings. He received the Presidential Award for Excellence in Science Teaching in 2009, served as a Teacher Ambassador Fellow at the U.S. Department of Education during the 201112 academic year, served as a National STEM Teacher Ambassador for the National Science Teachers 
Association (NSTA) \& the National Council of Teachers of Mathematics (NCTM) during the 2017-18 academic year, and he is currently serving a three-year term on the National STEM Education Advisory Panel. Wellman has also worked on several projects and consensus reports for the National Academy of Sciences and the National Academy of Engineering. 


\title{
Assessing Problem-Framing Skills in Secondary School Students Using the Needs Identification Canvas
}

\begin{abstract}
With programs like Project Lead The Way, engineering activities and curricula have increased in frequency in secondary school programs. In 2013, Next Generation Science Standards were published formalizing the importance of science and engineering practices in secondary schools as part of the 'Three Dimensions of Science Learning'. For a typical secondary science department, the current engineering options can either be very expensive and/or very time consuming (often requiring engineering courses outside of traditional science courses). The purpose of a broader NSF-funded project is to create and evaluate a more accessible system for engaging students in one of the key components of engineering design: problem framing.
\end{abstract}

This work presents one tool developed as part of that effort, the Need Identification Canvas (NIC), and the assessment methods developed for evaluating students' engineering problemframing skills using the NIC. The NIC is a tool for guiding novice designers through the need identification process, specifically addressing four key subcategories: stakeholders, stakeholder needs, a need statement, and information gathering. Student responses in each category were evaluated using a rubric, developed as part of this effort.

The canvas has been implemented with suburban high school biology, chemistry, physics, and physical science classes $(\mathrm{N}=55)$ as well as first-year engineering students $(\mathrm{N}=18)$ at a private undergraduate university to provide a basis of comparison for the higher levels of achievement. In addition to comparisons between grade levels, secondary students that have and have not been taking supplemental engineering courses as part of their program of study were compared. Significant differences were found amongst a variety of these subgroups.

\section{Introduction}

This study is part of a larger project to incorporate engineering problem-framing design actvities (EPDAs) into high school science classes. The most recent iteration of the Next Generation Science Standards [1] includes engineering as part of the disciplinary core ideas section of the performance expectations. Problem-framing activities are designed to help reach this measure in a manner that can be incorporated into high school science classes without a major overhaul.

Many of the current engineering efforts, like Project Lead The Way [2] may require a major overhaul to course offerings and may be quite expensive for schools to implement. The overarching goal with the "Building Informed Designers" project is to incorporate engineering design into existing high school science courses with minimal expense to improve design thinking and problem solving by all high school students. A secondary goal is to increase the number of students who will pursue college or community college engineering career pathways.

Problem solving and thus problem framing are a key first step of the engineering design process. Davis, Beyerlin, \& Davis [3] describes the role of a problem solver as one in which she "examines the problem setting to understand critical issues, assumptions, limitations, and 
solution requirements." Problem solving has been studied and found to be critical in design and decision making [4-8]. Complex problems can often be described as those that have more than one solution. These complex problems require problem solvers that can acquire relevant information [9], work within a context [10-13] and meet clients' needs [14-15].

The measure for evaluation in this study is the Need Identification Canvas (NIC). The NIC (Figure 1) is a tool that is used to help students isolate a problem by looking at the stakeholders. The four sub-categories for this instrument not only include the stakeholders (those that are affected), but also stakeholder needs, a need statement, and additional information that must be gathered before the problem is clearly defined.

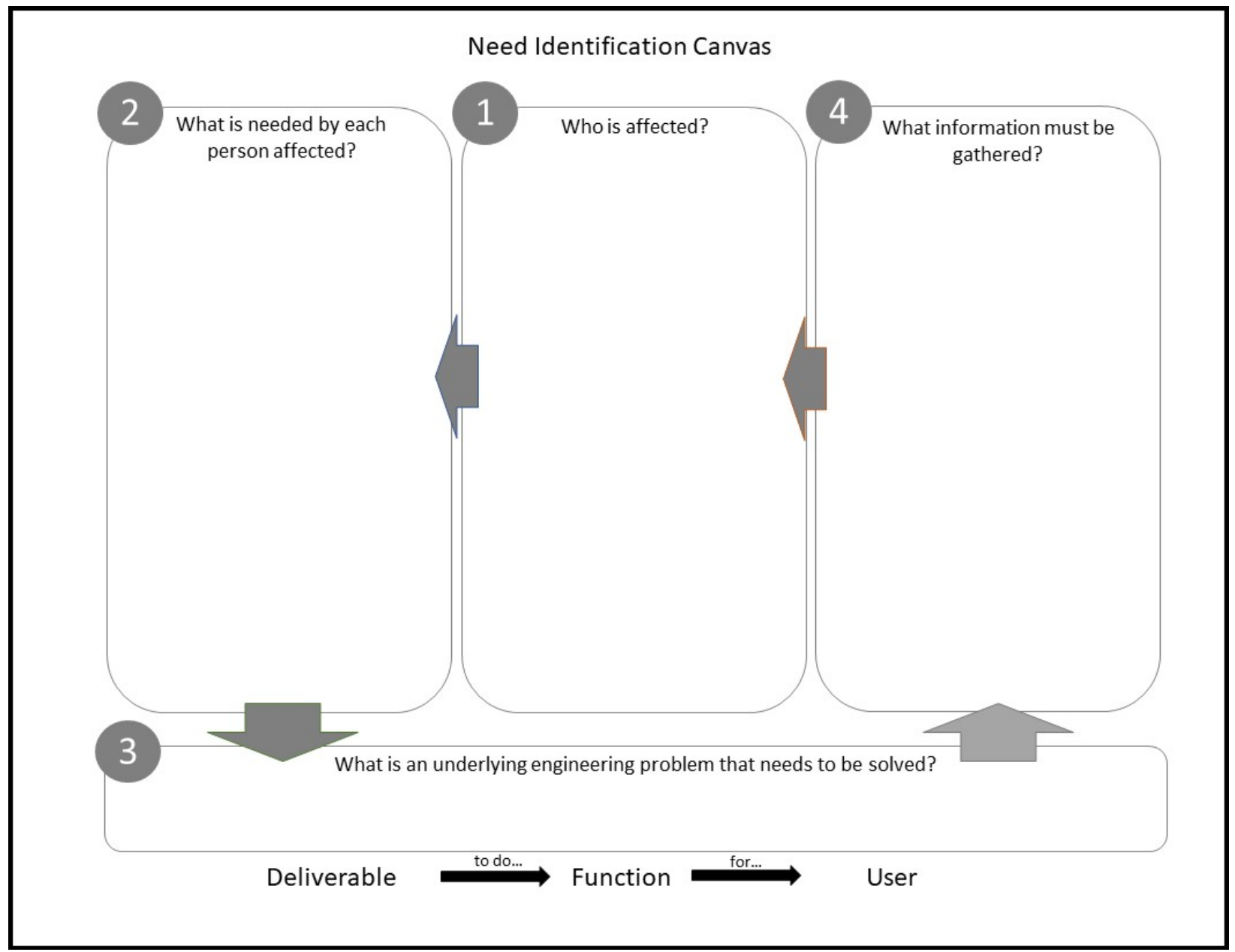

Figure 1. Need Identification Canvas

For each high school science course (biology, chemistry, physics, and physical science) crosscurricular scenarios are being developed. However, for the pilot study and instrument assessment, the scenario of building a spaceport is the focus. As students progress across courses, we plan to collect longitudinal data to measure improvement in student problemframing skills across semesters or even years. 


\section{Methods}

The research team developed an initial rubric for the NIC based upon four different levels: beginner, emerging, developing, and informed designer for each of the four sub-categories in the NIC (stakeholders, stakeholder needs, needs statement, and information gathering). One delimitation is that we believe these levels represent problem-framing skills at the interval, if not ratio level so that the assigned values of $1,2,3, \& 4$ have some meaning beyond a ranking.

A pilot implementation yielded student data that was then compared against the rubric by two research team members. Additionally, the student data was categorized into the four levels via face validity. After comparing face validity to rubric scores, the rubric went through several iterations until there was a consensus between scores and face validity.

Two Undergraduate Research Assistants (URAs) were trained to use the rubric to mark student NIC data. During training, two sample NICs were graded by the URAs with supervision from the Graduate Research Assistant (GRA). The GRA reviewed the scores and gave feedback on the scoring process and accuracy of the URAs.

The NIC was then administered to 55 high school students from three classes $(n=14,20, \& 21)$ as well as 18 first-year engineering students $(n=7 \& 11)$. The NIC was the first of several activities regarding problem framing. The NIC was administered after a brief introduction to the NIC and the Spaceport Scenario. Students were to brainstorm on their own without any additional resources. If this was a student's first introduction to the NIC (which it would be for all these students in the initial administration), it would serve the purpose of a pre-test. Students completed the NIC individually. After the administration of the NIC, students were engaged in several follow-up activities to address problem framing.

The NIC was then marked against the rubric by two URAs and one GRAs in a manner that each student's NIC was marked twice. The goal was to test for inter-rater reliability and to detect differences in high school v. university students.

Descriptive statistics (means and standard deviations), as well as T-tests for the two raters, and ANOVA for the multiple sub-categories were conducted.

\section{Results}

As expected, the university First-Year Engineering students outperformed secondary school students (Table 1) in both overall score and all sub-categories $(\mathrm{p}<0.01)$. This difference between the two groups is noteworthy given the large standard deviations, which will be discussed further regarding inter-rater reliability. 
Table 1. Mean and Standard Deviation of High School and First-Year Engineering Student scores on the NIC.

\begin{tabular}{|l|c|c|c|c|c|}
\cline { 2 - 6 } \multicolumn{1}{c|}{} & Stakeholders & $\begin{array}{c}\text { Stakeholder } \\
\text { Needs }\end{array}$ & $\begin{array}{c}\text { Needs } \\
\text { Statement }\end{array}$ & $\begin{array}{c}\text { Information } \\
\text { Gathering }\end{array}$ & Total \\
\hline High School & $1.65(0.83)$ & $1.81(0.77)$ & $1.20(0.50)$ & $1.33(0.61)$ & $1.5(0.41)$ \\
\hline $\begin{array}{l}\text { University } \\
\text { Engineering }\end{array}$ & $3.11(1.01)$ & $2.44(1.05)$ & $2.50(1.16)$ & $2.47(1.16)$ & $2.63(0.78)$ \\
\hline
\end{tabular}

Four Sub-Categories

A one-way ANOVA examining the differences in the four sub-categories between high school and university engineering students detects a significant difference $(p<0.01)$. After further examination, separating high school and university students yields some interesting results.

For high school students there was no significant difference between stakeholders/stakeholder needs or needs statement/information gathering; however, there was a significant difference $(\mathrm{p}<0.01)$ between stakeholder $(\mathrm{avg}=1.65)$ and both needs statement (avg=1.20) and information gathering (avg=1.33) as well as stakeholder needs (avg=1.81) and both needs statement and information gathering. These differences support the content validity of the NIC as the four subcategories loosely represent a progression towards framing the problem.

\section{Inter-rater Reliability}

In spite of our best efforts in training URAs, the scores produced by URAs marking the NIC $(a v g=1.93)$ were significantly higher $(\mathrm{p}<0.01)$ than the scores by the GRA $(\mathrm{avg}=1.53)$. There are a couple of potential reasons for this difference. First of all, while there is a reasonable sample size of student NICs, there is a limited number of URAs (two) and GRAs (one) marking the NIC.

Additionally, one would expect a graduate student to be at the informed designer level; However, the same assumption can not be made for an undergraduate engineering student. There exists a possibility that the URAs are only at the emerging or developing level themselves, which means they might tend to inflate scores thinking the NICs are better than they are.

Lastly, there are larger standard deviations in the university students, which should be expected as more are able to achieve higher levels. In spite of this larger standard deviation, there is still a significant difference between the two groups. 


\section{Conclusions and Recommendations}

The NIC can be an effective tool as it can clearly detect a difference between problem-framing skills and subskills of high school students and first-year engineering students. As students continue to participate in problem-framing activities, it will be important to continue to use the instrument to determine if growth can be detected. We plan to have this initial cohort of students repeat the NIC in different contexts that relate to their other science classes each year until they graduate. This follow-up should give us longitudinal data to help verify the instrument ability to detect improvement over time.

Additionally, inter-rater reliability must be addressed if large amounts of data are going to be processed. There are two current viewpoints to address this issue. First, training of URAs will need to be improved by either being more rigorous, more explicit, or both. A switch from online to in-person training may help address this concern. Second, it may be possible that URAs are simply not informed designers and are therefore not qualified to mark the NIC. It may be worth having any URA that is to be used as an NIC evaluator take the NIC themselves and reach a threshold score.

We hope that by continuing to follow this initial cohort of students, we can collect longitudinal data that shows they are prepared for engineering majors at the university level.

\section{References}

[1] "Next Generation Science Standards." [Online]. Available: https://www.nestgenscience.org/. [Accessed: 09-Jan-2018].

[2] "PLTW Engineering (9-12)," 2016. [Online]. Available: https://www.pltw.org/ourprograms/pltw-engineering-curriculum. [Accessed: 22-Nov-2019].

[3]Davis, D. C., Beyerlein, S. W. and I. T. Davis, Development and use of an engineer profile, Proc. American Society for Engineering Education Conf., Portland, OR, June 2005.

[4] Ennis Jr., C. W., and Gyeszly, S. W. (1991). Protocol analysis of the engineering systems. Res. Engineering Design, 3, 15-22.

[5] Mintzberg, H., Raisinghani, D., and Theoret, A. (1976). The structure of 'unstructured' decision processes. Admin. Sci. Quart., 21, 246-275.

[6] Volkema, R. J. (1983). Problem formulation in planning and design. Management Science, 29(6), 639-652.

[7] Volkema, R. J. (1986). Problem formulation as a purpose activity. Strategic Management Journal, 7(3), 267-279.

[8] Volkema, R. J. (1988). Problem complexity and the formulation process in planning and design. Behavioral Science, 33, 292-300.

[9] Mendonçka, A., Oliveira, C., Guerrero, D. and Costa, E. (2009) Difficulties in solving illdefined problems: A case study with introductory computer programming students. In Frontiers in Education Conference (FIE), San Antonio, TX.

[10] Elzey, D. (2006). Teaching intro to engineering in context - UVA engineering's new cornerstone. In Proceedings of the American Society of Engineering Education (ASEE) Annual Conference and Exposition. Chicago, IL.

[11] Neeley, K. A., Elzey, D., Bauer, D., and Marshall, P. (2004). Engineering in context: A 
multidisciplinary team capstone experience, incorporating real world constraints. In Proceedings of the American Society for Engineering Education (ASEE) Annual Conference and Exposition. Salt Lake City, UT.

[12] Bannerot, R., Wilson, C., \& Kastor, R. (2007). Improving students' understanding of the impact of engineering solutions in a global and societal context. Proceedings of the ASME 2007 International Mechanical Engineering Congress and Exposition, Seattle, Washington, 7, 31-37. doi: 10.1115/IMECE2007-43346

[13] Evans, J., and McGinnis, R. (2006). Short-term study abroad: engineering in a global and societal context. In American Society of Engineering Education (ASEE) Annual Conference and Exposition. Chicago, IL.

[14] Ansell, H. G. (1998). Professor-driven, student-driven, and client-driven design projects. In Frontiers in Education Conference (FIE), Washington D. C.

[15] Howard, T., \& Schwenk, C. (1983). Problem formulation and the consultant-client relationship. Interfaces, 13(5), 25-34. 


\section{Appendix}

Need Identification Canvas Rubric

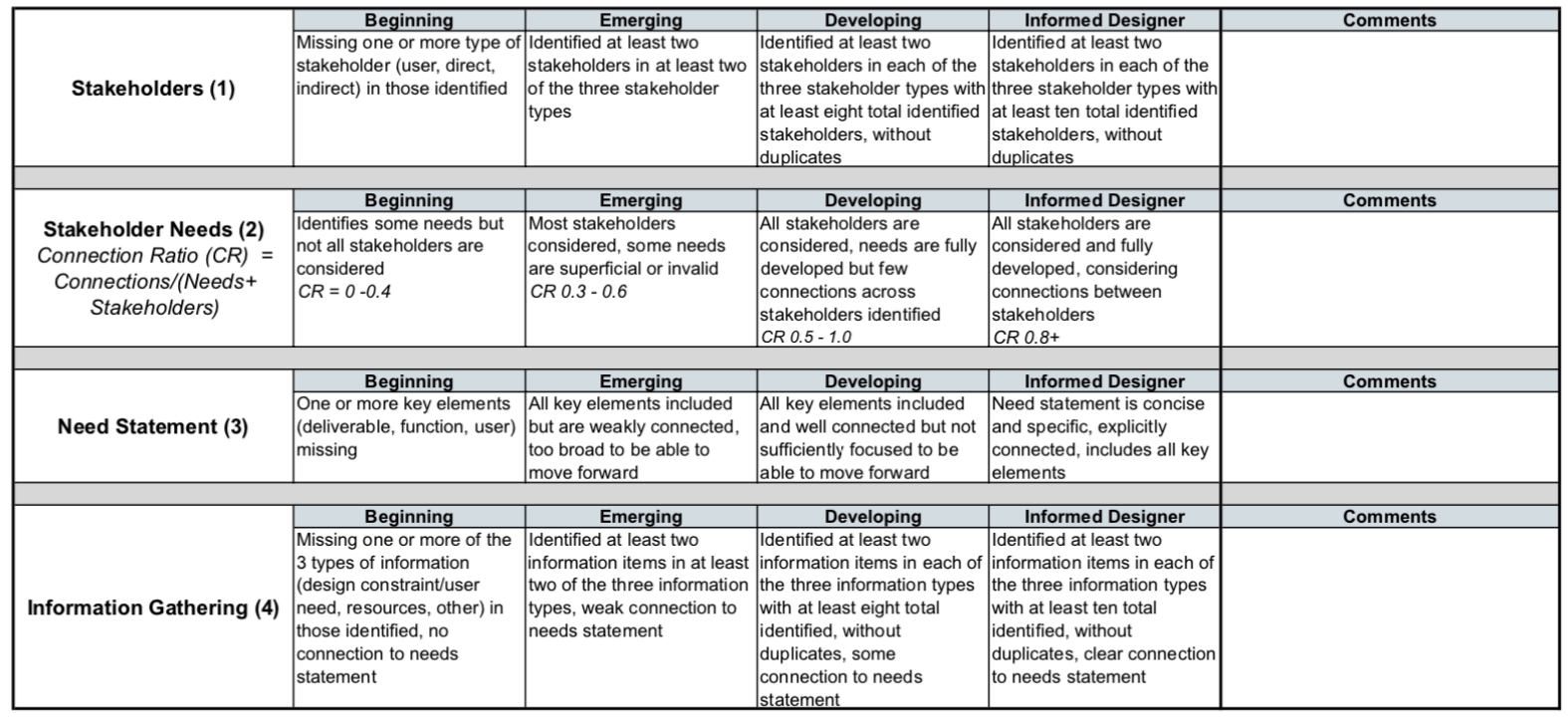

